\title{
Acne vulgar: diagnóstico e manejo pelo médico de família e comunidade
}

\author{
Acne vulgaris: diagnosis and management by the family physician \\ Acné vulgar: diagnóstico y manejo por el médico familiar y comunitario
}

Ana Margarida Ferreira da Silva. Unidade de Saúde Familiar das Ondas, Aces Porto IV. Póvoa de Varzim, Vila do Conde, Portugal. amargferreiradasilva@gmail.com (Autora correspondente)

Francisco Pinto da Costa. Unidade de Saúde Familiar das Ondas, Aces Porto IV. Póvoa de Varzim, Vila do Conde, Portugal.

franciscopintodacost@gmail.com

Margarida Moreira. Unidade de Saúde Familiar das Ondas, Aces Porto IV. Póvoa de Varzim, Vila do Conde, Portugal. mmargmoreira@gmail.com

\section{Resumo}

A acne vulgar é a doença cutânea mais frequente, afetando 85 a 100\% da população em algum momento da vida; constituindo, por isso, um motivo frequente de consulta na atenção primária à saúde. Geralmente, tem início na puberdade, situando-se o pico de incidência entre os 14 e 17 anos nas adolescentes, e entre os 16 e 19 anos nos rapazes, sendo mais grave e prevalente no sexo masculino. Apesar de extensamente debatida, a acne vulgar requer uma atualização constante. Foi feita uma revisão das diretrizes clínicas, meta-análises e revisões sistemáticas publicadas nos últimos 15 anos, relacionadas à acne vulgar e seu tratamento. Esta patologia é normalmente dividida em três tipos clínicos: comedônica, pápulo-pustulosa e nódulo-cística. 0 diagnóstico é clínico, contudo outros diagnósticos diferenciais devem ser considerados. Das várias opções terapêuticas farmacológicas disponíveis, destacam-se os retinoides, os antimicrobianos e a terapêutica hormonal, cuja utilização deve ser ponderada, tendo-se em conta as suas indicações - tipo de acne e sua gravidade - e os seus efeitos colaterais. Assim, o médico de família e comunidade desempenha um papel de primeira linha na abordagem da acne vulgar, desde o diagnóstico à gestão das opções terapêuticas.

\section{Abstract}

Acne vulgaris is the most common skin disease worldwide. It affects $85-100 \%$ of the population at any point in life. Consequently, it is a frequent reason for primary care visits. It usually begins at puberty, reaching its peak between the age of 14-17 in girls, and 16-19 in boys, and it is more severe and prevalent in males. Although widely discussed, Acne vulgaris still requires constant updating. We conducted a survey of clinical guidelines, systematic reviews, and meta-analyses published over the past 15 years, concerning acne vulgaris and its treatment. Acne vulgaris is usually divided in three clinical types: comedonal, papulopustular, and nodular. The diagnosis is based on clinical signs; however, other conditions should be considered. There are several pharmacological therapies available, especially retinoids, antimicrobials, and hormone therapy, which should be used after considering its indications (type of acne and its severity) and side effects. Thus, the family physician plays a leading role in addressing acne vulgaris, from diagnosis to management of therapeutic options.

\section{Resumen}

El acné vulgar es la enfermedad cutánea más frecuente, afectando del 85 al 100\% de la población en algún momento de su vida, lo que hace que sea un motivo frecuente de consulta en la atención primaria de salud. Generalmente se inicia en la pubertad, con un pico de incidencia entre las adolescentes de 14 a 17 años y entre los adolescentes de 16 a 19 años, siendo más grave y prevalente en el sexo masculino. A pesar de que éste sea un tema ampliamente discutido, precisase de una actualización constante, y, por eso motivo, se ha realizado una investigación de las directrices clínicas, metaanálisis y revisiones sistemáticas, publicadas en los últimos 15 años, relacionadas con el acné vulgar y su tratamiento. Esta patología normalmente se divide en tres tipos clínicos: comedónica, pápulo-pustulosa e nódulo-quística. El diagnóstico es clínico, sin embargo deben considerarse otros diagnósticos diferenciales. Dadas las distintas opciones terapéuticas farmacológicas disponibles, destacanse los retinoides, los antimicrobianos y la terapéutica hormonal, cuya utilización debe ponderarse teniendo en cuenta sus indicaciones (tipo de acné y su gravedad) y sus efectos colaterales. Por este motivo, el médico familiar y comunitario desempeña un papel de primera línea en el abordaje del acné vulgar, desde el diagnóstico hasta la gestión de las opciones terapéuticas.
Palavras-chave:

Acne vulgar

Terapêutica

Atenção Primária à Saúde
Keywords:

Acne Vulgaris

Therapeutics

Primary Health Care
Palabras clave: Acné Vulgar Terapéutica Atención Primaria de Salud 


\section{Introdução}

A acne vulgar é a doença cutânea mais frequente, afetando 85 a 100\% da população em algum momento da vida. É caracterizada por lesóes que resultam da ação dos hormônios sobre as glândulas sebáceas da pele, afetando as áreas com maior densidade de folículos sebáceos. ${ }^{1}$ Geralmente, tem início na puberdade, situando-se o pico de incidência nas adolescentes entre 14 e 17 anos, e nos rapazes entre 16 e 19 anos. A duração da doença é variável, podendo persistir na idade adulta em $50 \%$ das pessoas acometidas, ${ }^{2}$ e é possível, em alguns casos, deixar sequelas. Atinge ambos os sexos, sendo mais grave e prevalente no sexo masculino. ${ }^{3}$

É uma doença crônica do folículo pilossebáceo, cuja fisiopatologia é complexa e não totalmente compreendida. ${ }^{4}$ Envolve quatro fatores fisiopatológicos primários:

1. Hiperplasia das glândulas sebáceas e produção excessiva de sebo;

2. Hiperqueratinização folicular;

3. Colonização do folículo piloso pelo Propionibacterium acnes (P.acnes);

4. Inflamação e resposta imunológica.

Embora a acne não esteja associada a situaçôes de morbidade severa, incapacidade física ou mortalidade, tem significativas repercussóes físicas (cicatrizes), psicológicas (baixa autoestima, inibição social, depressão e ansiedade) e sociais (desemprego), que poderâo ser minimizadas com um tratamento precoce e adequado. ${ }^{5}$ Nos adolescentes tem um efeito negativo maior do que doenças como a asma e a epilepsia. ${ }^{6}$ Este distúrbio é frequentemente encarado como um processo normal do desenvolvimento e como um problema menor pelos pais, condicionando um atraso na procura por ajuda. O objetivo deste artigo é revisar a abordagem da acne vulgar em Atenção Primária.

\section{Estratégia de busca}

Revisão clássica narrativa com pesquisa, em março de 2012, na Medline e em sítios de Medicina Baseada em Evidências (National Guideline Clearinghouse, NHS Evidence, Canadian Medical Association, Evidence Based Medicine, InfoPOEMs, TRIP, The Cochrane library, DARE, Bandolier), de artigos publicados nos últimos 15 anos, com limite aos idiomas Português, Inglês e Espanhol. Utilizou-se como palavra-chave o termo MeSH 'Acne vulgaris'.

\section{Mitos e verdades}

$\mathrm{Na}$ sociedade atual, entre médicos e pacientes, persistem mitos e equívocos sobre a acne. Da mesma forma, algumas crenças, que antes se acreditava serem mitos, vêm sendo apoiadas por evidências que sustentam sua veracidade. A seguir, apresentamos as crenças mais frequentes a respeito da acne, juntamente com as evidências que as apoiam ou refutam:

- Dieta - Apesar de poucos estudos fidedignos correlacionarem a dieta com a acne, existe uma diferença de prevalência entre as sociedades industrializadas e não industrializadas, sugerindo-a como fator a considerar. Recentemente, foi encontrada uma relação entre a ingestáo de alimentos com carga glicêmica elevada e a patogênese da acne, através da hiperinsulinemia provocada por tais alimentos. ${ }^{1,7}$

- Higienização - Ainda persiste a ideia de que a acne está associada à higiene deficiente. ${ }^{1}$ Uma má higienização não só não provoca acne, como a evidência científica do papel da limpeza do rosto na patogênese da acne é de má qualidade. No entanto, sabe-se que a lavagem facial frequente e intempestiva tem sido proposta como sendo traumatizante, aumentando os efeitos de irritação cutânea da tretinoína tópica e da isotretinoína. ${ }^{7-10}$ Assim, o consenso geral é de que a limpeza do rosto deve ser efetuada uma vez por dia, com agente de limpeza ajustado ao tipo de pele, como preparação para a aplicação dos tratamentos posteriores. O recurso da maquiagem e das técnicas de camuflagem, desde que os produtos sejam não comedogênicos, não estão contraindicados. ${ }^{11,12}$ 
- Estresse - Desde longa data tem sido evocada a relaçáo causal entre o estresse e a acne, mas, apenas recentemente, Chiu et al. ${ }^{13}$ demonstraram correlação positiva entre o agravamento da acne e a existência de níveis elevados de estresse durante o período dos exames escolares.

- Atividade sexual - A prática sexual não demonstrou ter qualquer relação com a acne, pois são as alterações hormonais normais da puberdade que estão implicadas na sua patogênese. ${ }^{1}$

- Período menstrual - O agravamento pré-menstrual da acne pode ser parcialmente explicado pela diminuição do diâmetro de abertura do folículo dois dias antes do início da menstruação. ${ }^{1}$

- Exposição solar - Não existe evidência científica convincente do benefício da radiação ultravioleta sobre a acne. Recentes estudos sugeriram a eficácia de vários espectros de luz artificial, mas tais efeitos náo podem ser extrapolados para a luz solar. Além disso, a fotossensibilidade é um efeito colateral comum a muitos tratamentos médicos para a acne. ${ }^{7}$

\section{Classificação}

Nấo existe um sistema universal de classificação da acne vulgar. Neste artigo, adotamos um sistema de classificação em que, com base no predomínio de lesôes elementares encontradas (Quadro 1), se definem três tipos de acne: comedônica, pápulo-pustulosa e nódulo-cística - ou apenas nodular. ${ }^{1,14}$ Isso não significa, entretanto, que, em um tipo de acne, não possam estar presentes outros tipos de lesôes. ${ }^{14}$

O estadiamento da acne deve levar em conta uma avaliação global da gravidade - classificada em leve, moderada ou grave/severa -, representando uma síntese entre tipo, número, tamanho e extensão das lesôes, e auxiliando na seleção de agentes terapêuticos apropriados e na avaliação da resposta ao tratamento. ${ }^{15}$

\section{Diagnóstico diferencial}

O diagnóstico da acne vulgar é clínico, sendo geralmente fácil distinguir as diferentes formas - comedônica, pápulopustulosa e nódulo cística (Figuras 1, 2 e 3). Porém, pontualmente podem surgir dificuldades, devendo ser levados em consideraçáo alguns diagnósticos diferenciais (Quadro 2), ${ }^{1,14,16}$ cujas imagens podem ser consultadas em www.dermis.net ${ }^{17}$ (considerar que a nomenclatura pode ser ligeiramente diferente).

Quadro 1. Termos utilizados para descrição das lesões. ${ }^{1}$

\begin{tabular}{ll}
\hline Comedão & Lesão elementar da acne, surgindo em consequência da hiperceratose de retenção do folículo pilossebáceo. \\
Pápula & Área de eritema e edema em redor do comedão, com pequenas dimensões (até $3 \mathrm{~mm}$ ). \\
Pústula & Conteúdo purulento e normalmente doloroso, acompanhado de prurido. \\
Nódulo & Idêntico à pápula, mas com dimensões de até $2 \mathrm{~cm}$. \\
Cisto & Grande comedão que sofre várias rupturas e recapsulações, contendo um conteúdo pastoso e caseoso. \\
Cicatriz & Depressão irregular coberta de pele atrófica, resultante da destruição do folículo pilossebáceo por reação inflamatória. \\
\hline
\end{tabular}

Quadro 2. Diagnósticos diferenciais a serem considerados. ${ }^{1,14,16}$

\begin{tabular}{ll}
\hline Mília & $\begin{array}{l}\text { Pequenas pápulas esbranquiçadas e de localização periorbitária. } \\
\text { Ceratose pilar }\end{array}$ \\
Foliculites bacterianas & Limitam-se à área da barba e podem ser causadas por Estafilococos ou Gram-negativos. Podem apresentar-se como pápulo-pústulas \\
& ou nódulos deprimidos. \\
Pseudofoliculite da barba & Frequente na etnia negra, caracteriza-se por pápulas, por vezes pústulas e cicatrizes, com localização preferencial na região cervical. \\
Acne iatrogênica & Pápulo-pústulas monomorfas, de pequenas dimensões, em relação temporal com o fármaco. \\
Dermatite perioral & Pequenas pápulas e pústulas sobre base eritematosa, tipicamente poupando uma margem de pele sã em torno dos lábios. \\
Rosácea & Pequenas pápulo-pústulas eritematosas sobre fundo telangiectásico, distribuídas pelas áreas convexas do nariz, regiões malares, \\
& frontais e mento, sobretudo na mulher pré-menopáusica. \\
Pioderma facial & Pápulo-pústulas e nódulos coalescentes no mento e nas regiões nasogenianas e frontais, podendo ser acompanhado de sintomas \\
& sistêmicos (Figura 4). \\
\hline
\end{tabular}




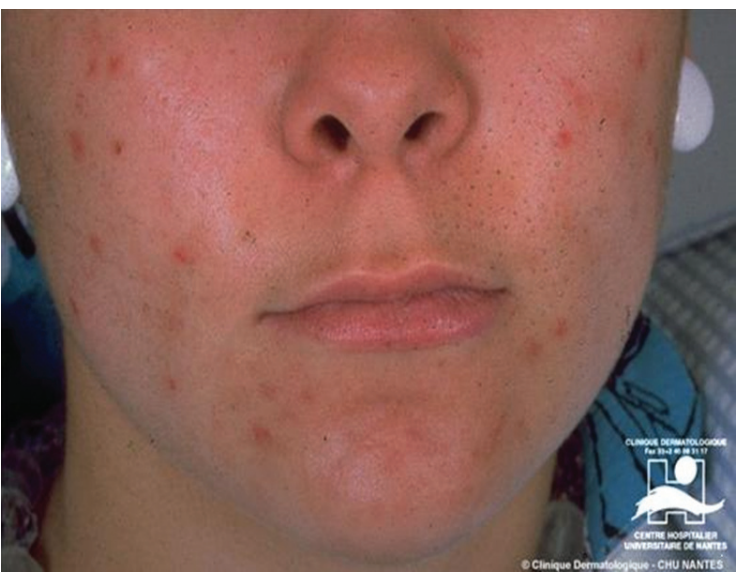

Figura 1. Acne comedônica.

Fonte: Dermatology Online Atlas. ${ }^{17}$

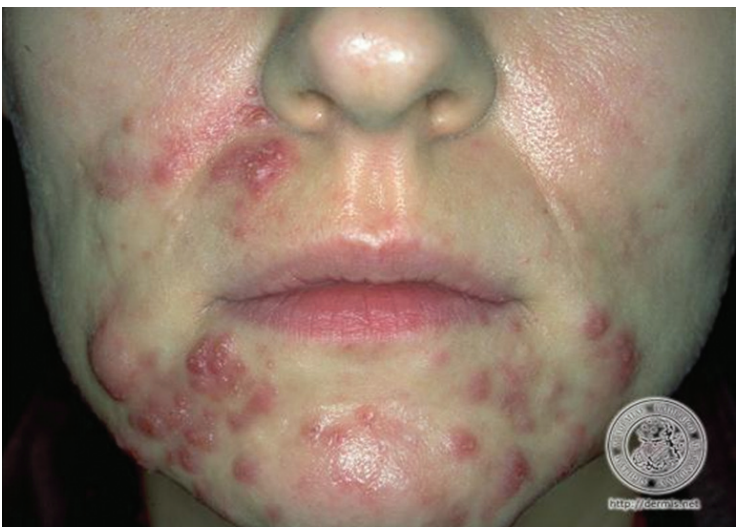

Figura 3. Acne nódulo-cística.

Fonte: Dermatology Online Atlas. ${ }^{17}$

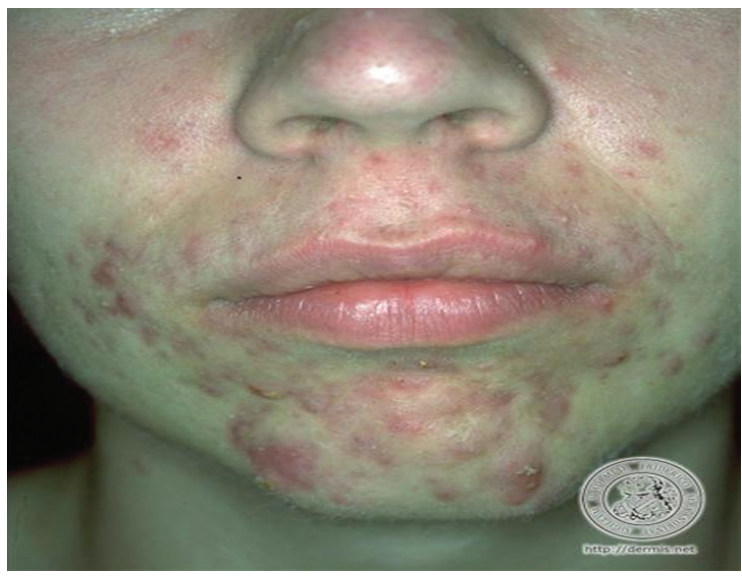

Figura 2. Acne pápulo-pustulosa. Fonte: Dermatology Online Atlas. ${ }^{17}$

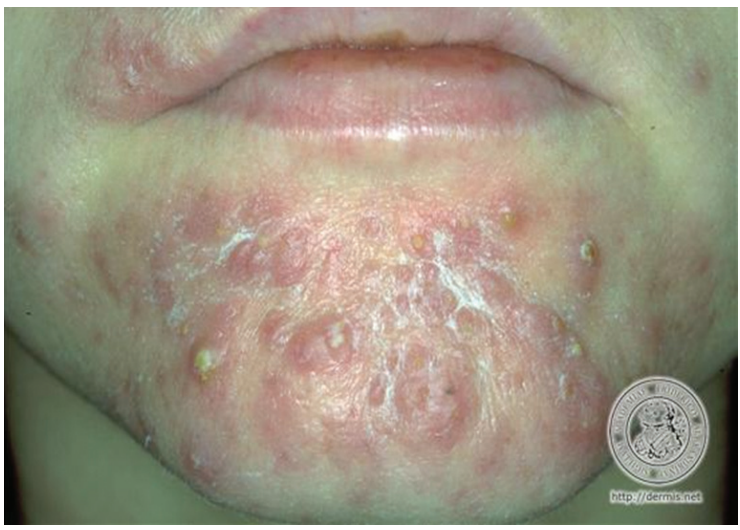

Figura 4. Pioderma facial.

Fonte: Dermatology Online Atlas. ${ }^{17}$

\section{Exames auxiliares de diagnóstico}

$\mathrm{Na}$ maioria dos casos, tais exames não são necessários. No entanto, perante suspeita de hiperandroginismo (dada por hirsutismo, irregularidades menstruais e alopécia androgenética, por exemplo), preconiza-se ponderar pedido de estudo hormonal. ${ }^{1}$

\section{Tratamento}

Para aumentar a adesão, é fundamental utilizar esquemas simples adaptados, com não mais de três fármacos, desfazer mitos e capacitar a pessoa em relação à doença e ao seu tratamento. ${ }^{18,19} \mathrm{Na}$ orientação do tratamento da acne, optamos por seguir o algoritmo da Global Alliance $e^{3}$ (Figura 5).

\section{Tratamento tópico}

A aplicação tópica deve ser realizada sobre toda a área afetada, com preparaçóes de baixa concentração, com aumento posterior da frequência ou da dose, se necessário. ${ }^{19}$ Dentro dos tratamentos tópicos, preferir cremes em caso de pele seca; preparaçôes na forma de gel, em caso de pele oleosa; e soluçôes, se necessário aplicar em zonas extensas ou com grande densidade pilosa. ${ }^{3,18,19}$ 


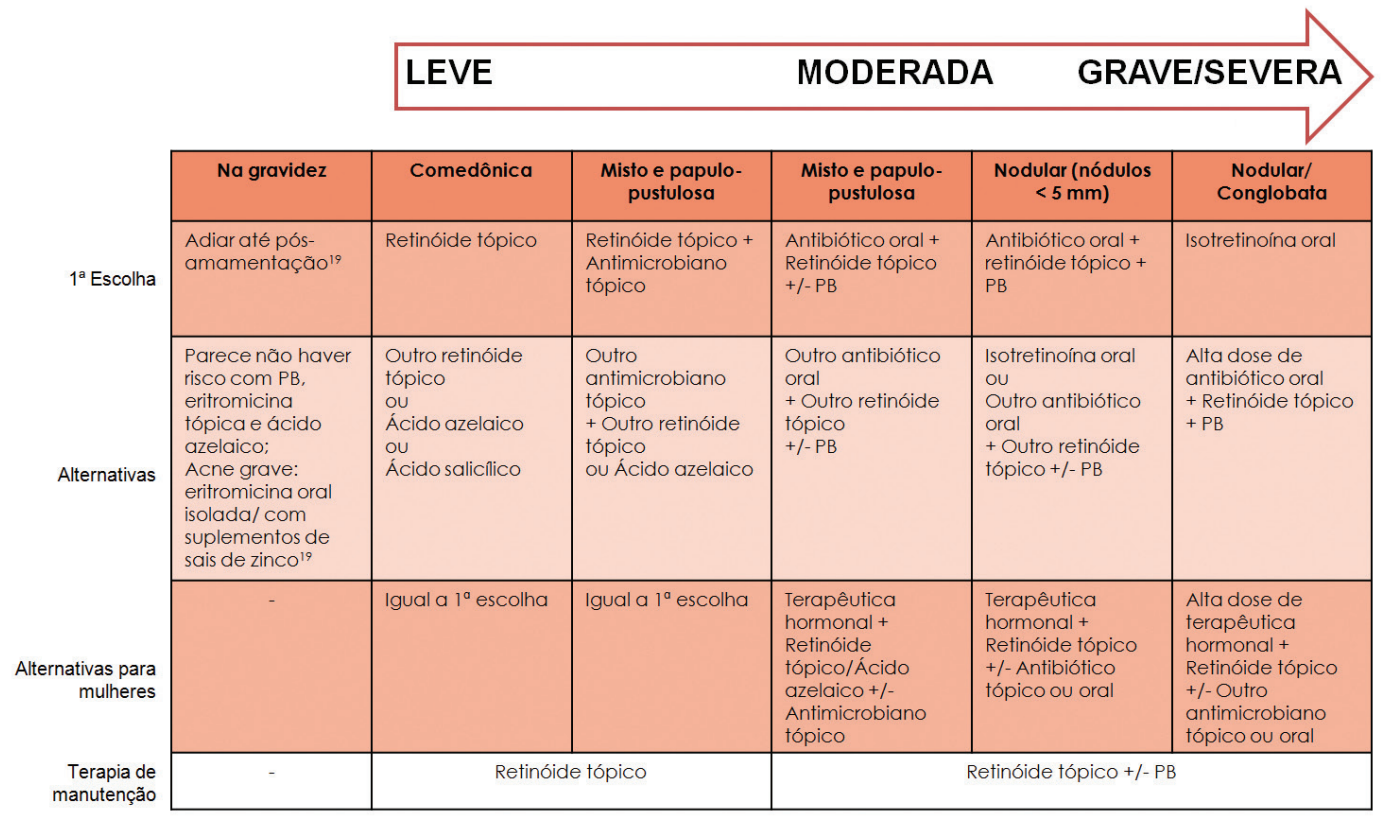

Figura 5. Algoritmo de tratamento da acne (adaptado de Global Alliance Acne Treatment Algorithm). ${ }^{3}$

PB - peróxido de benzoíla.

\section{Retinoides tópicos}

Atuam como comedolíticos e anticomedogênicos, mas têm também efeitos anti-inflamatórios e facilitam a penetração de outros agentes tópicos. ${ }^{3,18}$

São considerados produtos de primeira linha (de forma isolada ou em combinaçáo) na acne leve a moderada. ${ }^{20}$ Os mais comuns são o adapaleno, a isotretinoína e a tretinoína, todos apresentando atividade comedolítica semelhante (Quadro 3). ${ }^{20}$

A isotretinoína e a tretinoína têm, como potenciais efeitos adversos, irritação, intolerância solar e secura cutânea, necessitando ser aplicadas à noite. $\mathrm{O}$ adapaleno está associado a menor potencial irritante e é mais estável à luz (pode ser aplicado de manhâ). ${ }^{20}$

Para evitar efeitos colaterais, os retinoides tópicos podem ser iniciados em baixas concentraçóes, podendo mesmo ser utilizados em noites alternadas inicialmente, após lavar a face com agente de limpeza suave. Deve-se ainda aplicar diariamente hidratante com proteção solar. ${ }^{19}$

Todos os retinoides são contraindicados na gravidez e na amamentação. As mulheres em idade fértil devem utilizar métodos contraceptivos eficazes. ${ }^{19}$

\section{Peróxido de benzoíla (PB)}

É uma preparação segura com ação comedolítica e antimicrobiana, podendo ser usada isoladamente ou em associação com retinoides tópicos ou antibióticos tópicos ou orais. ${ }^{19}$

Devido à oxidaçáo da tretinoína pelo $\mathrm{PB}$, esses fármacos náo devem ser aplicados de forma concomitante; se for necessário o uso combinado, deve-se aplicar o PB de manhã e a tretinoína à noite. A associação mais habitual é a de PB com adapaleno, à noite..$^{20,21}$

Uma associação frequentemente recomendada é a de PB com antibiótico tópico ou oral, pois a ação bactericida do PB promove um menor desenvolvimento de resistência bacteriana e melhor tolerabilidade, sendo que ambos os fármacos atuam sinergicamente na reduçấo do $P$. acnes. ${ }^{3,20,21}$

Está recomendado o uso de $\mathrm{PB}$ em concentraçóes baixas (2,5\% ou 5\%), uma vez que é menos irritante e igualmente eficaz. ${ }^{19}$ Deve-se advertir para o fato de este causar descoloração do cabelo e roupas. ${ }^{18,20,21}$ 


\section{Antibióticos tópicos}

Parecem atuar sobre a acne inflamatória leve através de ação antimicrobiana sobre o $P$. acnes e ação anti-inflamatória. ${ }^{19,20}$ Estão disponíveis a clindamicina e a eritromicina, que devem ser aplicadas duas vezes ao dia (Quadro 3). ${ }^{22}$

Devido à preocupação com o desenvolvimento de resistência bacteriana, defende-se que o uso dos antibióticos tópicos seja interrompido logo que as lesóes inflamatórias comecem a se resolver, o que ocorre em 2 a 6 semanas, devendo as lesôes ser reavaliadas em 6 a 8 semanas e ponderando-se substituição por PB. ${ }^{20,21}$

Quadro 3. Fármacos e formulações disponíveis para o tratamento da acne. ${ }^{18,19,20,22}$

\begin{tabular}{|c|c|}
\hline \multicolumn{2}{|l|}{ Retinoides } \\
\hline \multirow[t]{2}{*}{ Adapaleno } & Creme: $1 \mathrm{mg} / \mathrm{g}$ \\
\hline & Gel: $1 \mathrm{mg}$ \\
\hline \multirow[t]{3}{*}{ Isotretinoína } & Gel: 0,05\% \\
\hline & Creme: $0,5 \mathrm{mg}$ \\
\hline & Comprimido: 10mg, 20mg \\
\hline \multirow[t]{2}{*}{ Tretinoína } & Creme: $0,025 \%, 0,05 \%, 0,1 \%$ \\
\hline & Gel: $0,01 \%, 0,025 \%, 0,05 \%$ \\
\hline \multicolumn{2}{|l|}{ Antibióticos } \\
\hline \multicolumn{2}{|l|}{ Tetraciclinas } \\
\hline Tetraciclina & Comprimido: $500 \mathrm{mg}$ \\
\hline Doxiciclina & Comprimido: $100 \mathrm{mg}$ \\
\hline Minociclina & Comprimido: 50mg, $100 \mathrm{mg}$ \\
\hline \multicolumn{2}{|l|}{ Macrólidos } \\
\hline \multirow[t]{3}{*}{ Eritromicina } & Gel: 20mg/g \\
\hline & Solução tópica: 20mg/mL \\
\hline & Comprimido: 500mg \\
\hline \multirow[t]{2}{*}{ Azitromicina } & Comprimido: 500mg \\
\hline & Suspensão oral: 600mg/15mL \\
\hline \multicolumn{2}{|l|}{ Clindamicina } \\
\hline & Gel: $10 \mathrm{mg} / \mathrm{g}$ \\
\hline & Comprimido: $300 \mathrm{mg}$ \\
\hline \multicolumn{2}{|c|}{ Trimetoprim/Sulfametoxazol } \\
\hline & Comprimido: $160 \mathrm{mg} / 800 \mathrm{mg}$ \\
\hline \multicolumn{2}{|l|}{ Peróxido de benzoíla } \\
\hline & Tópico: 2,5\%, 5\%, 10\% \\
\hline \multicolumn{2}{|l|}{ Ácido salićlíco } \\
\hline & Tópico: 1-5\% \\
\hline \multicolumn{2}{|l|}{ Ácido azelaico } \\
\hline & Gel: 150mg/g \\
\hline & Creme: $200 \mathrm{mg} / \mathrm{g}$ \\
\hline \multicolumn{2}{|l|}{ Terapêutica combinada } \\
\hline Eritromicina + Isotretinoína & Gel: $20 \mathrm{mg} / \mathrm{g}+0,5 \mathrm{mg} / \mathrm{g}$ \\
\hline Adapaleno + PB & Gel: $1 \mathrm{mg} / \mathrm{g}+25 \mathrm{mg} / \mathrm{g}$ \\
\hline Adapaleno + Clindamicina & Gel: $10 \mathrm{mg} / \mathrm{g}+1 \mathrm{mg} / \mathrm{g}$ \\
\hline Clindamicina + PB & Gel: $10 \mathrm{mg} / \mathrm{g}+50 \mathrm{mg} / \mathrm{g}$ \\
\hline \multicolumn{2}{|c|}{ Terapêutica hormonal (comprimido) } \\
\hline COC segunda geração & Levonorgestrel + EE (doses variáveis) \\
\hline \multirow[t]{2}{*}{ COC terceira geração } & Desogestrel + EE (doses variáveis) \\
\hline & Gestodeno + EE (doses variáveis) \\
\hline COC quarta geração & Trimegestona $0,125 \mathrm{mg}+$ estradiol $1 \mathrm{mg}$ \\
\hline \multirow[t]{4}{*}{ COC com antiandrogênios } & EE $35 \mu \mathrm{g}+$ acetato de ciproterona $2 \mathrm{mg}$ \\
\hline & $\mathrm{EE} 30 \mu \mathrm{g}+$ dienogeste $2 \mathrm{mg}$ \\
\hline & EE 20 ou 30 $\mu \mathrm{g}$ + drospirenona 3mg \\
\hline & $\mathrm{EE} 30 \mu \mathrm{g}+$ clormadinona $2 \mathrm{mg}$ \\
\hline
\end{tabular}

COC - contraceptivo oral combinado; EE - etinilestradiol; PB - Peróxido de benzoíla. 


\section{Outros tratamentos}

\section{Ácido azelaico}

Possui propriedades antimicrobianas, comedolíticas e anti-inflamatórias, sendo usado como segunda linha. Pode causar hipopigmentação. ${ }^{19}$ Recomenda-se a aplicação inicial noturna (creme a 20\%), podendo-se aumentar até 2 a 3 vezes por dia. Pode ser usado na gestação e é útil no verão e em pessoas que não toleram os retinoides tópicos, pois não produz fotossensibilidade. ${ }^{18,21}$

\section{Ácido salicílico}

É um esfoliante, com caraterísticas queratolíticas e anti-inflamatórias, podendo associar-se a retinoides tópicos no tratamento da acne comedônica ou como tratamento de segunda linha. Não há estudos que apoiem a utilização rotineira do ácido salicílico em detrimento de outras terapias. ${ }^{19}$

\section{Tratamento oral}

\section{Antibióticos orais}

São normalmente usados nos casos de acne mais grave, acne predominantemente no tronco e acne que não responde à terapia tópica, ou em pacientes com maior risco de cicatrizes, uma vez que têm início de ação mais rápido que os antibióticos tópicos e são igualmente bem tolerados. ${ }^{19,20}$

Os antibióticos orais preferidos são as tetraciclinas e os macrolídeos (Quadro 3). ${ }^{18,19}$ Das tetraciclinas, as opções são a doxiciclina e a minociclina, na dose de $100-200 \mathrm{mg} / \mathrm{dia}$, em tomada única diária, reduzindo para $50 \mathrm{mg} /$ dia quando há melhora, e a tetraciclina na dose de $500 \mathrm{mg} /$ dia, não podendo esta ser ingerida com lácteos ou alimentos (ingerir uma hora antes ou duas horas após). ${ }^{18,19}$

Em relação aos efeitos colaterais, devemos alertar para a intolerância digestiva (devem ser tomados com água e fora das refeiçôes, visto que os alimentos diminuem a sua absorção); no entanto, defende-se que, para melhor adesão, possa ser aconselhada a sua ingestão durante as refeiçôes (exceto no caso da tetraciclina). ${ }^{18}$ As tetraciclinas também podem causar descoloração dentária e estão contraindicadas em gestantes e crianças. ${ }^{18,21}$

A doxiciclina pode causar fotossensibilidade. ${ }^{21} \mathrm{~A}$ minociclina tem sido associada a distúrbios vestibulares, deposição de pigmento e, raramente, lúpus eritematoso sistêmico induzido por drogas, que geralmente ocorre no início do tratamento. Os pacientes que tomam minociclina devem avaliar a funçáo hepática (através da dosagem das aminotransferases) a cada 3 a 4 meses. ${ }^{18}$

Os macrolídeos - eritromicina (250-500mg, 2 vezes/dia), azitromicina (500mg, 2 vezes/dia, 3 dias seguidos/semana) e, eventualmente, a claritromicina -, além de problemas de desconforto gastrointestinal, têm uma eficácia cada vez mais limitada dado o perfil de resistência do $P$. acnes, pelo que devem ser reservados para os casos de intolerância ou contraindicação às tetraciclinas, ou quando se pretende fazer tratamento no verão. ${ }^{18,20}$

As quinolonas ou o sulfametoxazol-trimetoprim (800/160mg, 2 vezes/dia) devem ser considerados de terceira linha. ${ }^{18,20}$

$\mathrm{O}$ uso de antibióticos tem sido associado a casos de resistência bacteriana, sobretudo quando utilizados em doses baixas por longos períodos; assim, recomenda-se que sejam usados por, no mínimo, 6 a 8 semanas e, no máximo, 4 meses, devendo ser interrompidos se não houver melhora. ${ }^{18-20}$ 
O antibiótico oral nunca deve ser usado em monoterapia, mas sempre com um agente tópico - retinoide tópico, ou, nos casos de administração superior a 2 meses, com o PB, para reduzir a resistência bacteriana. ${ }^{18-20}$ Nunca se deve associar o mesmo antibiótico tópico e oral. ${ }^{18,19}$ Em caso de recidiva, após tratamento bem sucedido, deve ser prescrito o mesmo antibiótico. ${ }^{18-20}$

Se o paciente demonstra um agravamento da acne enquanto estiver usando antibióticos orais, tal pode ser causado por resistência bacteriana ou foliculite gram-negativa; esta requer a utilização de ampicilina ou, de preferência, isotretinoína. ${ }^{18}$ O desenvolvimento de foliculite gram-negativa, como resultado de tratamento com antibiótico oral, pressupóe a suspensão deste, não devendo ser reiniciado.

\section{Terapêutica hormonal}

É uma excelente escolha para as mulheres com agravamento pré-menstrual da acne, acne na idade adulta, acne envolvendo preferencialmente a metade inferior da face e pescoço, associada à seborreia; hirsutismo, e irregularidades do ciclo menstrual, com ou sem hiperandrogenismo, e para jovens sexualmente ativas com acne inflamatória.

Os contraceptivos orais combinados (COCs), contendo um estrogênio [etinilestradiol (EE)] associado a um progestágeno de segunda geração (levonorgestrel, noretindrona) ou de terceira geração (desogestrel, norgestimato e gestodeno), ou a um antiandrogênio (acetato de clormadinona, ciproterona, dienogeste, trimegestona e drospirenona), são frequentemente prescritos (Quadro 3). ${ }^{18,20}$

Contraceptivos só com progestágeno, incluindo o DIU com liberação de levonorgestrel, frequentemente pioram a acne e devem ser evitados em mulheres com acne sem contraindicaçôes para estrogênios.

\section{Isotretinoína oral}

É geralmente reservada para a acne nódulo-cística severa com cicatrizes ou acne resistente a outras terapias. É o fármaco que interfere de forma mais completa nos mecanismos fisiopatológicos da acne. ${ }^{20}$

A administração de isotretinoína, por cerca de 20 semanas, resulta em cura clínica em aproximadamente $85 \%$ dos casos. O tratamento deve ser realizado com doses diárias de $0,5-1 \mathrm{mg} / \mathrm{kg}$ por dia (em 2-3 tomadas/dia, após as refeiçōes) ou um total de $120-150 \mathrm{mg} / \mathrm{kg}$ ao longo da duração do tratamento (6 a 8 meses). Para evitar exacerbação da doença, pode-se iniciar com uma dose mais baixa $(0,5 \mathrm{mg} / \mathrm{kg} / \mathrm{dia})$ durante o primeiro mês e depois aumentar para $1 \mathrm{mg} / \mathrm{kg} / \mathrm{dia}$.

A ingesta da medicação não deve ser associada a outros agentes comedolíticos tópicos ( $\mathrm{PB}$, retinoides) por agravamento da irritação cutânea, nem a tetraciclinas por risco de diminuir o efeito antiacneico e de causar hipertensão intracraniana.

A isotretinoína causa fotossensibilidade, queilite seca, xerose, epistaxe e agravamento temporário de lesóes, mas raramente graves o suficiente para causar a interrupção do tratamento. Devido à teratogenicidade associada, as pacientes em idade fértil devem usar método contraceptivo altamente eficaz, iniciando um mês antes do uso da isotretinoína até um mês após o término do uso. Testes de gravidez negativos devem ser obtidos antes, durante e 5 semanas após o término do tratamento. Segundo a portaria SVS/MS 344/98, ${ }^{23}$ a receita deve ser acompanhada de Notificação de Receita para retinoides de uso sistêmico (C2), bem como pela assinatura de Termo de Consentimento Pós-Informação.

Poderão ocorrer alteraçôes nos perfis lipídico e hepático e nas plaquetas, motivo pelo qual é aconselhável a realização de controle analítico antes do início e após 4-6 semanas de tratamento. ${ }^{20}$

A prescrição de isotretinoína oral na Atenção Primária não é consensual. Contudo, uma diretriz ${ }^{15}$ sublinha que, dados os potenciais efeitos adversos deste fármaco, este deva ser prescrito unicamente por médicos que tenham conhecimento acerca da sua administração apropriada e monitorização. Tal não afasta por completo a possibilidade de esta poder ser usada no nível da Atenção Primária, mas exige experiência e confiança por parte do médico prescritor que deve proceder de acordo com a legislação em vigor. 


\section{Terapia de manutenção}

É obrigatória após tratamento com sucesso, prevenindo o aparecimento de novas lesões e resolvendo as existentes.

Os retinoides tópicos são os candidatos ideais. Nos casos mais graves, a associação com um agente antimicrobiano pode ser necessária, podendo o PB ser adicionado.

\section{Medidas gerais}

O paciente deve ser aconselhado a lavar e secar suavemente a zona afetada, uma vez ao dia, com agente de limpeza próprio e suave. Devido ao efeito irritativo da terapêutica, devem-se usar cremes ou emulsóes sem óleo, sendo fundamental evitar manipulação das lesōes. ${ }^{20}$

O tratamento tópico deve ser aplicado em toda a área afetada, após lavagem, com a pele seca, evitando o contato com mucosas. Quando se associam vários tratamentos tópicos, separadamente, deve-se intervalar a sua aplicação em pelo menos uma hora. Porém, as combinaçóes de tratamentos tópicos assim comercializadas (retinoides + antibióticos, PB + antibióticos ou $\mathrm{PB}+$ retinoides) são mais eficazes do que a aplicação dos componentes isoladamente e favorecem uma maior adesão, pelo que, neste caso, são vantajosas (Quadro 3). ${ }^{21} \mathrm{~A}$ melhoria das lesôes só aparece várias semanas após o início do tratamento. ${ }^{21}$

\section{Prognóstico}

A acne vulgar tende a desaparecer espontaneamente depois da adolescência. Desconhece-se por que persiste em alguns adultos. A melhoria das lesôes não é imediata após início do tratamento, podendo mesmo piorar temporariamente. Inicialmente, deve-se reavaliar a cada 14 dias e depois mensalmente, para avaliar a evolução e os efeitos colaterais. ${ }^{21}$

\section{Conclusão}

O médico de família e comunidade desempenha um papel de primeira linha na abordagem da acne vulgar. Por este motivo, deverá estar apto a lidar com a maioria das situaçóes apresentadas no cotidiano, provendo um suporte educacional e delineando estratégias terapêuticas atualizadas e apropriadas a cada caso. O objetivo terapêutico será o de proporcionar resolução das lesôes existentes, prevenção do aparecimento de cicatrizes e de novas lesôes, e um incremento da autoestima do indivíduo afetado. Além disso, é importante promover a adesão a um tratamento em que os resultados não são imediatos e devem ser reavaliados; note-se, também, que a autossuspensão da terapêutica pode representar um retrocesso.

Alguns casos merecerão referenciação ao dermatologista, nomeadamente situaçôes em que os objetivos terapêuticos não sejam atingidos, com acne resistente ao tratamento, quando há cicatrizes significativas ou quando há suspeita de determinadas situaçóes, como acne fulminante (acne severa, de aparecimento súbito, com febre e poliartralgias) ou complicaçóes da acne. ${ }^{22}$ Quando o paciente tem indicação de isotretinoína oral, em geral é encaminhado para o dermatologista, embora médicos de família e comunidade possam prescrever esse fármaco desde que tenham experiência e segurança para isso, seguindo a legislação em vigor. ${ }^{15}$

\section{Referências}

1. Figueiredo A, Massa A, Picoto A, Soares AP, Basto AS, Lopes C, et al. Avaliação e tratamento do doente com acne - Parte I: Epidemiologia, etiopatogenia, clínica, classificação, impacto psicossocial, mitos e realidades, diagnóstico diferencial e estudos complementares. Rev Port Clin Geral. 2011 Jan-Feb;27:59-65.

2. Dréno B, Poli F. Epidemiology of Acne. Dermatology. 2003;206(1):7-10. http://dx.doi.org/10.1159/000067817 
3. Thiboutot D, Gollnick H, Bettoli V, Dréno B, Kang S, Leyden JJ, et al. New insights into the management of acne: an update from the Global Alliance to improve outcomes in Acne group. J Am Acad Dermatol. 2009 May; 60(5 Suppl):S1-50. http://dx.doi.org/10.1016/j.jaad.2009.01.019

4. Pawin H, Beylot C, Chivot M, Faure M, Poli F, Revuz J, et al. Physiopathology of acne vulgaris: recent data, new understanding of the treatments. Eur J Dermatol. 2004 Jan-Feb;14(1):4-12.

5. Carvalho A, Mourão A, Assunção C, Fonseca C, Gama D, Oliveira L, et al. Acne: prevalência e factores associados. Patient Care. Edição Portuguesa. 2010 Fev; 15(156):59-65.

6. Mallon E, Newton J, Klassen A, Stewart-Brown SL, Ryan TJ, Finlay AY. The quality of life in acne: a comparison with general medical conditions using generic questionnaires. Br J Dermatol. 1999 Apr;140(4):672-6. http://dx.doi.org/10.1046/j.1365-2133.1999.02768.x

7. Magin P, Pond D, Smith W, Watson A. A systematic review of the evidence for myths and misconceptions in acne management: diet, face-washing and sunlight. Fam Pract. 2005 Feb;22:62-70. http://dx.doi.org/10.1093/fampra/cmh715

8. Gollnick H, Cunliffe W. Management of acne: general management strategies in acne. J Am Acad Dermatol. 2003 Jul;49(1):S30-1.

9. Dunlap FE, Mills OH, Tuley MR, Baker MD, Plott Rt. Adapalene 0,1\% gel for the treatment of acne vulgaris: its superiority compared to tretinoin 0,025\% cream in skin tolerance and patient preference. Br J Dermatol. 1998 Oct;139(52):17-22.

10. Millikan LE. Pivotal clinical trials of adapalene in the treatment of acne. J Eur Acad Dermatol Venereol. 2001;15(3):19-22.

11. Poli F. Soins cosmetiques et acne. Rev Prat. 2002 Avr15;52(8):859-62.

12. Hayashi N, Imori M, Yanagisawa M, Seto Y, Nagata O, Kawashima M. Make-up improves the quality of life acne patients without aggravating acne eruptions during treatments. Eur J Dermatol. 2005 Jul-Aug;15(4):284-7.

13. Chiu A, Chon SY, Kimball AB. The response of skin disease to stress: changes in the severity of acne vulgaris as affected by examination stress. Arch Dermatol. 2003 Jul;139(7):897-900. http://dx.doi.org/10.1001/archderm.139.7.897

14. Wolff K, Goldsmith LA, Katz SI, Gilchrest BA, Paller AS, Leffell DJ. Fitzpatrick's Dermatology in General Medicine. 7th edition. New York: McGraw-Hill Medical; 2008.

15. Strauss J, Krowchuck D, Leyden J, Lucky AW, Shalita AR, Siegfried EC, et al. Guidelines of care for acne vulgaris management. J Am Acad Dermatol. 2007 Apr;56:651-63. http://dx.doi.org/10.1016/j.jaad.2006.08.048

16. Wolff K, Johnson R, Suurmond R. Fitzpatrick Dermatologia - Atlas e Texto. 5a ed. Rio de Janeiro: McGraw-Hill; 2006.

17. Diepgen TL, Yihune G, Schuler G, Tanko Z, Lohrmann H, Paessler J et al. Dermatology Online Atlas. [acesso em 2013 Dez 9]. Disponível em: dermis.net

18. Katsambas AD, Stefanaki C, Cunliffe, WJ. Guidelines for treating acne. Clin Dermatol. 2004 Sep-Oct;22(5):439-44. http://dx.doi.org/10.1016/j. clindermatol.2004.03.002

19. Williams HC, Dellavalle RP, Garner S. Acne vulgaris. Lancet. 2012 Jan;379(9813):361-72. http://dx.doi.org/10.1016/S0140-6736(11)60321-8

20. Figueiredo A, Massa A, Picoto A, Soares AP, Basto AS, Lopes C, et al. Avaliação e tratamento do doente com acne - Parte II: Tratamento tópico, sistémico e cirúrgico, tratamento da acne na grávida, algoritmo terapêutico. Rev Port Clin Geral. 2011 Jan-Feb;27:66-76.

21. Martin-Zurro A, Cano Pérez JF. Atención Primaria. 5a ed. Madrid: Elsevier; 2003.

22. Feldman S, Careccia RE, Barham KL, Hancox J. Diagnosis and treatment of acne. Am Fam Physician. 2004 May; 69(9):2123-2130.

23. Ministério da Saúde (BR), Secretaria de Vigilância em Saúde. PORTARIA № 344, DE 12 DE MAIO DE 1998. Aprova o Regulamento Técnico sobre substâncias e medicamentos sujeitos a controle especial. Brasília, DF; 1988. Disponível em: http://bvsms.saude.gov.br/bvs/saudelegis../svs/1998/ prt0344_12_05_1998_rep.html 